\title{
Hamster Adrenal Carcinoma
}

National Cancer Institute

\section{Source}

National Cancer Institute. Hamster Adrenal Carcinoma. NCI Thesaurus. Code C134990.

Carcinoma arising from the adrenal gland and occurring in a hamster. 